\title{
Accumulation of noncoding RNA due to an RNase $P$ defect in Saccharomyces cerevisiae
}

\author{
MICHAEL C. MARVIN, ${ }^{1}$ SANDRA CLAUDER-MÜNSTER, ${ }^{2}$ SCOTT C. WALKER, ${ }^{1}$ ALI SARKESHIK, ${ }^{3}$ \\ JOHN R. YATES III, ${ }^{3}$ LARS M. STEINMETZ, ${ }^{2}$ and DAVID R. ENGELKE ${ }^{1,4}$ \\ ${ }^{1}$ Department of Biological Chemistry, University of Michigan, Ann Arbor, Michigan 48109-0606, USA \\ ${ }^{2}$ European Molecular Biology Laboratory, 69117 Heidelberg, Germany \\ ${ }^{3}$ Department of Chemical Physiology, The Scripps Research Institute, La Jolla, California 92037, USA
}

\begin{abstract}
Ribonuclease $\mathbf{P}$ (RNase $\mathbf{P}$ ) is an essential endoribonuclease that catalyzes the cleavage of the $5^{\prime}$ leader of pre-tRNAs. In addition, a growing number of non-tRNA substrates have been identified in various organisms. RNase $P$ varies in composition, as bacterial RNase $P$ contains a catalytic RNA core and one protein subunit, while eukaryotic nuclear RNase P retains the catalytic RNA but has at least nine protein subunits. The additional eukaryotic protein subunits most likely provide additional functionality to RNase $P$, with one possibility being additional RNA recognition capabilities. To investigate the possible range of additional RNase $P$ substrates in vivo, a strand-specific, high-density microarray was used to analyze what RNA accumulates with a mutation in the catalytic RNA subunit of nuclear RNase P in Saccharomyces cerevisiae. A wide variety of noncoding RNAs were shown to accumulate, suggesting that nuclear RNase P participates in the turnover of normally unstable nuclear RNAs. In some cases, the accumulated noncoding RNAs were shown to be antisense to transcripts that commensurately decreased in abundance. Pre-mRNAs containing introns also accumulated broadly, consistent with either compromised splicing or failure to efficiently turn over pre-mRNAs that do not enter the splicing pathway. Taken together with the high complexity of the nuclear RNase $P$ holoenzyme and its relatively nonspecific capacity to bind and cleave mixed sequence RNAs, these data suggest that nuclear RNase $P$ facilitates turnover of nuclear RNAs in addition to its role in pre-tRNA biogenesis.
\end{abstract}

Keywords: Ribonuclease P; IncRNA; RNA turnover

\section{INTRODUCTION}

Nuclear ribonuclease $\mathrm{P}$ (RNase P) in Saccharomyces cerevisiae plays an essential role in maturing the $5^{\prime}$ end of pretRNA via an endonucleolytic cleavage (for review, see Frank and Pace 1998; Walker and Engelke 2006). In bacteria the holoenzyme contains a large, catalytic RNA subunit and a small protein subunit that stabilizes the folding of the catalytic RNA and helps to bind pre-tRNA substrate leader sequences (for review, see Smith et al. 2007; Koutmou et al. 2009). In addition, a recent crystal structure of the bacterial holoenzyme complex with mature tRNA reinforced earlier biochemical results by showing that the protein subunit acts to primarily distinguish between tRNA product and pre-tRNA substrate via interaction with the $5^{\prime}$ leader (Reiter et al. 2010). The simple bacterial enzyme primarily recognizes substrate structure, and several additional nontRNA substrates have been previously identified (Bothwell

\footnotetext{
${ }^{4}$ Corresponding author.

E-mail engelke@umich.edu.

Article published online ahead of print. Article and publication date are at http://www.rnajournal.org/cgi/doi/10.1261/rna.2737511.
}

et al. 1976; Peck-Miller and Altman 1991; Giegé et al. 1993; Alifano et al. 1994; Komine et al. 1994; Liu and Altman 1994; Hartmann et al. 1995; Jung and Lee 1995; Gimple and Schön 2001; Hansen et al. 2001; Li and Altman 2003; Altman et al. 2005; Wilusz et al. 2008). The archaeal and eukaryotic nuclear enzymes are far more complex, and although they retain the catalytic RNA subunit, they have multiple proteins with largely unknown functions (for review, see Walker and Engelke 2006). The yeast nuclear enzyme has nine essential protein subunits in addition to the RNA subunit, Rpr1r (Lee et al. 1991; Chamberlain et al. 1998). Like its bacterial counterpart, in addition to pre-tRNA, other possible substrates have been identified in eukaryotes (Chamberlain et al. 1996; Yang and Altman 2007; Coughlin et al. 2008; Wilusz et al. 2008). In addition, purified nuclear RNase P's affinity for single-stranded RNA and its ability to cleave at multiple sites in vitro without obvious sequence specificity (see Marvin et al. 2011) indicate a broad capacity to serve as a relatively nonspecific RNA endonuclease.

In an earlier study showing RNase P bound to many RNAs in vivo, we used double-stranded probes to entire open reading frames (ORFs) that did not discriminate between 
sense and antisense transcripts (Coughlin et al. 2008). To obtain a more nuanced view of what transcripts are sensitive to a well-characterized mutation in the catalytic RNA subunit of nuclear RNase P, we have examined the cellular RNA population at high resolution in a strand-specific, highdensity microarray. The results show surprisingly broad RNA accumulations, primarily of normally unstable noncoding RNAs and short-lived pre-mRNAs containing introns. The results are discussed in the context of a possible endonucleolytic role for nuclear RNase P in the turnover of RNA that does not enter defined pathways for ribonuclear protein (RNP) assembly or mRNA utilization.

\section{RESULTS}

\section{High-density, strand-specific identification of RNAs that accumulate in an RNase $P$ temperature-sensitive mutant}

We have previously identified several RNase P temperaturesensitive (ts) mutations that result in the accumulation of
pre-tRNA (Pagán-Ramos et al. 1996; Xiao et al. 2005, 2006). One of the ts mutations used in this study of Rpr1r, the catalytic RNA subunit of RNase $\mathrm{P}$, is implicated in magnesium coordination and primarily affects the $k_{\text {cat }}$ for pretRNA substrates (Pagán-Ramos et al. 1996). Although the mutation is lethal at $37^{\circ} \mathrm{C}$, there are also significant defects under conditions that allow growth. As seen in Supplemental Figure S1, pre-tRNA ${ }^{\text {Leu }}$ accumulates strongly at both $37^{\circ} \mathrm{C}$ and $30^{\circ} \mathrm{C}$ in the ts strain relative to an otherwise isogenic wild-type (wt) strain, confirming previous observations of severely defective RNase $\mathrm{P}$ activity.

Using high-density, strand-specific microarrays, we determined how RNA levels change with the RNase P mutation relative to wild type at $30^{\circ} \mathrm{C}$ and $37^{\circ} \mathrm{C}$. Table 1 shows a summary of the most highly enriched RNAs organized by type of encoded gene product, taken from the larger list provided with numerical values in Supplemental Table S1. Two classes of RNA that were the most affected by the RNase P mutation were a large variety of noncoding RNAs from across the genome and ribosomal protein mRNA containing introns, both large and small subunits. The great majority of the most

TABLE 1. Top nuclear-encoded RNAs that enrich with RNase P mutation

Ribosomal small subunit mRNAs

Ribosomal large subunit mRNAs

Cryptic unstable transcripts (CUTs) (36/925)

Stable unannotated transcripts (SUTs) (45/847)

Core Sm transcripts

Other transcripts containing introns

Uncharacterized or unknown function transcripts

Miscellaneous transcripts
RPS10A (3.64), RPS29A (2.93), RPS10B (2.73), RPS25A (2.63), RPS18B (2.42), RPS4A (2.40), RPS30A (1.96), RPS6B (1.92), RPS19A (1.91), RPS26B (1.73), RPS19B (1.70), RPS21B (1.67), RPS16A (1.67), RPS23B (1.54), RPS24B (1.42), RPS30B (1.35), RPS8A (1.35), RPS29B (1.32), RPS24A (1.22), RPS26A (1.18), RPS27B (1.17)

RPL27B (3.84), RPL39 (3.77), RPL37A (3.73), RPL34B (3.72), RPL26B (3.46), $\underline{R P L 13 B}$ (3.21), RPL34A (3.01), RPL37B (2.97), RPL19B (2.82), RPL31A (2.58), $\overline{R P L 23 B}$ (2.35), $\overline{R P L 36 A}$ (2.17), $\overline{R P L 14 A}$ (2.09), $\underline{R P L 40 B}$ (2.07), $\overline{R P L 27 A}$ (2.04), $\underline{R P L 40 A}$ (2.02), $\underline{R P L 43 A}$ (1.90), $\underline{R P L 29}$ (1.86), $\underline{R P L 33 A}$ (1.80), $\underline{R P L 33 B}$ (1.77), RPL35B (1.73), RPL21A (1.56), RPL7A (1.52), RPL26A (1.46), RPL6A (1.26), RPL14B (1.26)

CUT324 (2.50), CUT526 (2.43), CUT680 (2.22), CUT843 (2.07), CUT008 (1.82), CUT073 (1.66), CUT128 (1.62), CUT846 (1.58), CUT149 (1.58), CUT732 (1.53), CUT523 (1.52), CUT347 (1.51), CUTO09 (1.49), CUT249 (1.47), CUT461 (1.39), CUT734 (1.39), CUT168 (1.36), CUT055 (1.35), CUT595 (1.32), CUT190 (1.31), CUT894 (1.30), CUT791 (1.29), CUT085 (1.28), CUTO46 (1.27), CUT572 (1.25), CUT376 (1.24), CUT689 (1.22), CUT456 (1.22), CUT125 (1.22), CUT325 (1.21), CUT432 (1.21), CUT440 (1.20), CUT030 (1.20), CUT676 (1.18), CUT837 (1.17), CUT238 (1.17)

SUT582 (2.03), SUT677 (1.96), SUT741 (1.96), SUT116 (1.81), SUT625 (1.76), SUT139 (1.68), SUT699 (1.67), SUT248 (1.65), SUT631 (1.62), SUT279 (1.61), SUT205 (1.61), SUT517 (1.61), SUT249 (1.58), SUTO74 (1.57), SUT542 (1.57), SUT343 (1.56), SUT287 (1.55), SUT771 (1.53), SUT101 (1.49), SUTO45 (1.46), SUT442 (1.43), SUT129 (1.42), SUTO08 (1.42), SUT346 (1.42), SUT814 (1.39), SUT035 (1.39), SUT827 (1.37), SUT200 (1.36), SUT636 (1.35), SUT313 (1.34), SUT700 (1.34), SUT553 (1.31), SUT844 (1.31), SUT535 (1.30), SUT756 (1.29), SUT617 (1.29), SUT278 (1.28), SUT691 (1.26), SUT519 (1.25), SUT808 (1.25), SUT347 (1.25), SUTO01 (1.20), SUT411 (1.20), SUT404 (1.19), SUT114 (1.19) SMD3 (1.49)

DYN2 (1.48)

YNR073C (2.01), YOR053W (1.83), YIL127C (1.58), COS12 (1.46), YGR121W-A (1.45), YGR169C-A (1.43), YJL144W (1.39), YNL162W-A (1.26), YOLO14W (1.21), YKRO75W-A (1.18)

AIF1 (2.01), SOM1 (1.79), ATG8 (1.66), SPG4 (1.66), YCLO58W-A (1.48), QCR9 (1.40), MAG1 (1.31), SNR9 (1.30), JID1 (1.17)

Accumulation values are indicated in parenthesis for $37^{\circ} \mathrm{C}$ only with an arbitrary cutoff of 1.17 . Full listing of the most enriched RNAs can be found in the Supplemental Data. Underlined RNAs have one or more intron(s). 
accumulated mRNAs were from intron-containing genes, although a smaller number of other mRNA and uncharacterized ORF transcripts are also represented in Table 1.

CUT and SUT noncoding RNA were identified in recent studies that investigated the prevalence of transcription in the yeast genome, in which as much as $85 \%$ of the genome was found to be transcribed (David et al. 2006; Neil et al. 2009; Xu et al. 2009; for review, see Jacquier 2009). These two classes of RNA were differentiated by relative stability, with CUTs, which are normally rapidly degraded, stabilized enough for detection by a deletion mutant of an exonuclease component of the nuclear exosome, RRP6 (for review, see Vanacova and Stefl 2007). Both of these noncoding RNA classes are transcribed by RNA polymerase II, with many of them transcribed in the opposite direction of associated protein-coding gene promoters (Neil et al. 2009; Xu et al. 2009). CUTs are typically $200-600 \mathrm{nt}, 5^{\prime}$-capped, and have heterologous $3^{\prime}$ ends (for review, see Jacquier 2009). SUTs are usually longer then CUTs with an average length of 761 nt (Xu et al. 2009). The two classes are not rigidly differentiated since independent methods were used to identify them in multiple studies (Neil et al. 2009; Xu et al. 2009).

The accumulation of CUT and SUT noncoding RNA shown in Table 1 is also presented visually with expression maps shown in Figure 1. Figure 1A-D shows a representative sample of regions corresponding to CUTs and SUTs that are enriched in the temperature-sensitive mutant at the nonpermissive temperature.

Accumulated protein-coding mRNAs were largely intron-containing as represented by the underlined RNAs in Table 1 and illustrated in Figure 2. This is a highly specific group of pre-mRNAs, since in S. cerevisiae introns are only present in $\sim 5 \%$ of genes (Spingola et al. 1999; Juneau et al. 2006; Roy and Gilbert 2006). Of this small percentage of genes that have introns, ribosomal protein genes dominate with $71 \%$ containing one or more introns (Planta and Mager 1998). Table 1 indicates that the majority of most accumulated intron-containing mRNAs encode for ribosomal proteins, with one exception (DYN2). Importantly, all of the top enriched mRNA that encodes for ribosomal protein contained introns (Supplemental Table S1). Thus, the accumulation of a high number of mRNAs coding for ribosomal protein appears to correlate with the presence of introns and not simply being a ribosomal protein mRNA.

To determine if other introns were accumulating that we might not have observed in Table 1, because the intron is only a small part of the overall gene signal, we used visual inspection of the transcript map of the entire genome (http://steinmetzlab.embl.de/engelkeArray/index.html) to identify the changes in mRNA intron abundance compared to corresponding exon signals (for examples, see Fig. 2). It was clear that the introns of ribosomal protein pre-mRNAs

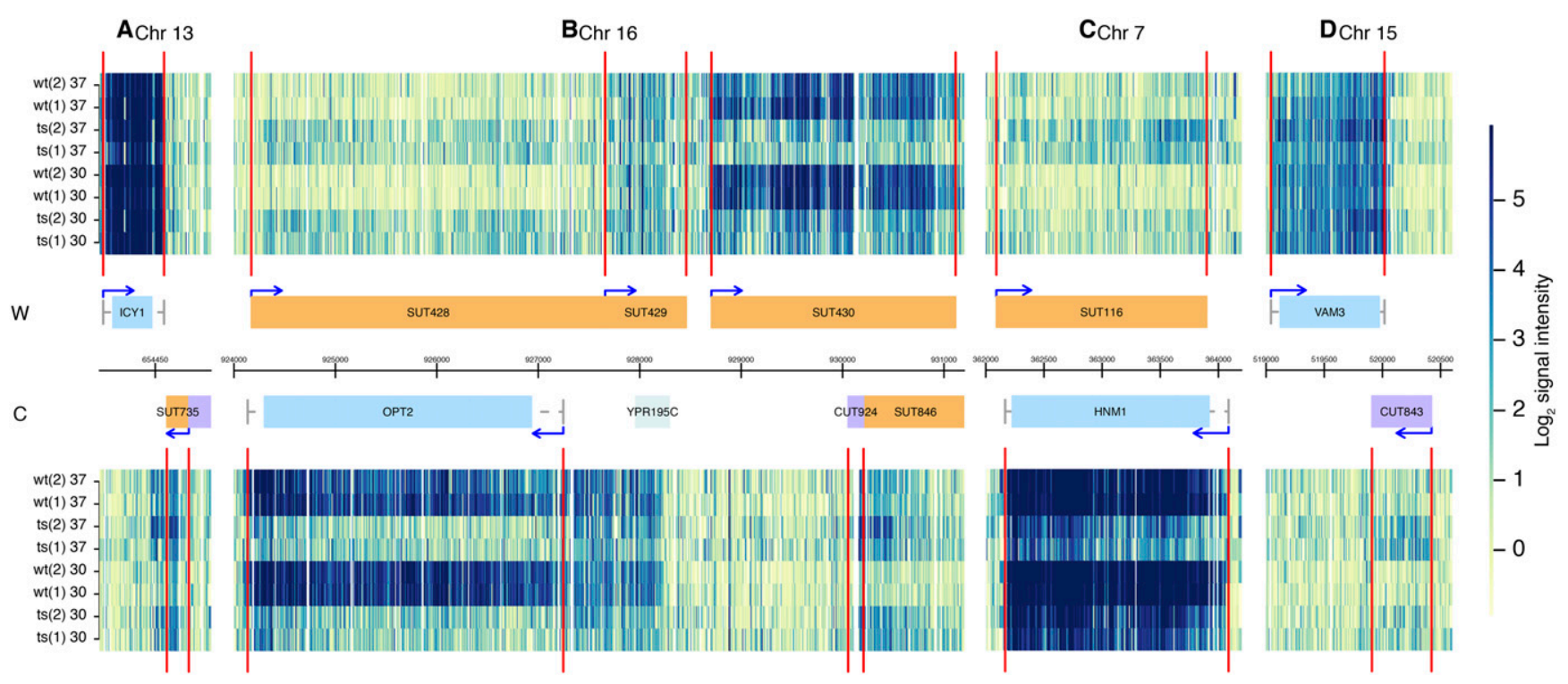

FIGURE 1. Noncoding RNA accumulates in an RNase P mutant strain. RNA expression data are shown along various positions of the indicated chromosomes for the Watson $(\mathrm{W}, t o p)$ and the Crick $(\mathrm{C}$, bottom $)$ strands. Abundance data across the whole genome are found in a searchable online database (see Materials and Methods). Normalized signal intensities are shown for indicated samples. Biological replicates for either wildtype (wt) or RNase P mutant (ts) strains were grown at either $30^{\circ} \mathrm{C}$ or $37^{\circ} \mathrm{C}$ in synthetic media. (Vertical red lines) Inferred positions of transcription boundaries. Genome annotations are shown in the center with annotated open reading frames (ORFs) (blue) and untranslated regions (UTRs) (gray lines). (Orange boxes) Previously annotated (Xu et al. 2009) SUTs; (purple boxes) CUTs; (light blue box) an uncharacterized ORF; (arrows) direction of transcription. Coordinates are indicated in base pairs in the center. $(A-D)$ Examples of SUTs $(A-C)$ and CUTs $(B, D)$ accumulating in the RNase $\mathrm{P}$ ts strain at either $30^{\circ} \mathrm{C}$ or $37^{\circ} \mathrm{C} .(B, C)$ Reciprocal examples in which ORF RNAs decline in abundance with the RNase P mutation, while antisense RNAs accumulate. As shown in A, sometimes the inferred transcription boundaries (Xu et al. 2009) do not precisely align with the apparent expression in these experiments. This could reflect larger RNAs being present in the RNase P mutants. 


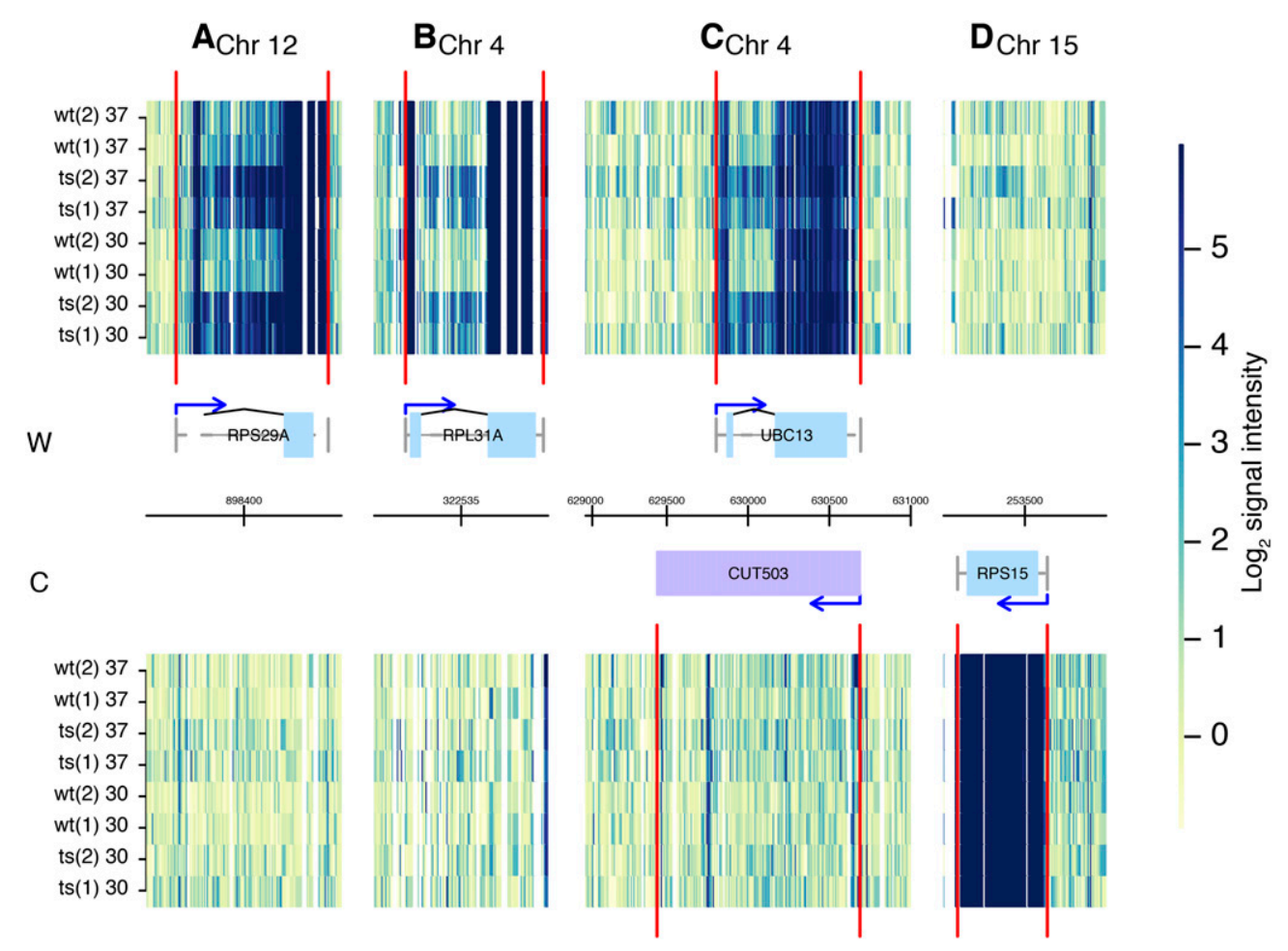

FIGURE 2. Introns accumulate in an RNase $\mathrm{P}$ mutant strain. Examples are shown of intron accumulation, with representations as in Figure 1. (Gray lines) Introns and untranslated $5^{\prime}$ or $3^{\prime}$ segments of transcripts outside the ORFs are shown connecting ORF exons (blue boxes). (Blue arrows) Transcript starts; (black arched lines) known splicing events. Panel $A$ does not show a blue box for the $5^{\prime}$ exon because the intron is part of the $5^{\prime}$ UTR. $(A-C)$ Examples of introns accumulating in mRNA-coding regions with RNase P mutation, either ribosomal protein mRNA $(A, B)$ or nonribosomal protein mRNA $(C)$, compared to a ribosomal mRNA not containing an intron $(D)$. An overlapping CUT in $C$ does not show significant change in abundance at this locus.

and other intron-containing pre-mRNAs were selectively enriched. A typical ribosomal protein mRNA that does not contain an intron is shown in Figure 2D for comparison. Intron-containing messages where the intron accumulates are listed in Table 2. These include many that are not represented in Table 1, since the majority of the signal strength that defines accumulation of genes in Table 1 derives from the much stronger exon signals.

\section{Sense/antisense RNA balance affected by defective RNase P}

A number of noncoding RNAs, 36 out of 925 total annotated CUTs and 45 out of 847 total annotated SUTs, were among the most enriched transcripts in the RNase $\mathrm{P}$ mutant strain. Upon inspection of the transcript map results (http://steinmetzlab.embl.de/engelkeArray/index.html), some interesting changes were evident (Fig. 1A-D). In addition to cases of CUT and SUT RNA accumulation, sometimes the sense and antisense changes were inverse in the RNase $\mathrm{P}$ mutant (Fig. 1B,C; Supplemental Fig. S2A). In addition, some cases were observed where an unannotated RNA accumulated while an overlapping ORF showed de-enrichment (Supplemental Fig. S2B). For two cases, enrichment of SUT RNAs that are antisense to de-enriched ORF RNAs was confirmed by Northern blots (Fig. 3A,B). These results also indicated that the SUT RNA was accumulating in multiple larger forms, as large as $6000 \mathrm{nt}$, rather than only the smaller forms observed previously (Fig. 3). The annotations of the boundaries of CUTs and SUTs were mapped differentially using, in the case of CUTs, an automated segmentation algorithm in an Rrp6 deletion strain, or in the case of SUTs, automated segmentation followed by manual curation in wild-type cells ( $\mathrm{Xu}$ et al. 2009). The appearance of these various sizes coincides with a reciprocal loss of overlapping mRNA signal at these loci. The exact nature of these larger SUT RNAs, whether they are precursors of the smaller RNAs, and how they might be related to loss of transcripts from the opposing strand remains to be investigated. These multiple sizes, added to the fact that the RNase P mutant accumulates overlapping but nonidentical noncoding RNAs, suggest that the RNase $\mathrm{P}$ mutant is not affecting precisely the same turnover events as seen with the Rrp6 deletion mutant in previous work (Xu et al. 2009).

\section{Confirmation of intron-containing pre-mRNA accumulation}

We used Northern blots and semi-quantitative RT-PCR analyses of total RNA to confirm microarray results for 
TABLE 2. Top mRNA introns affected by RNase $P$ mutation

Enriched RPL27B, RPL39, RPL37A, RPL34B, RPS10A, RPL26B, RPL13B, RPL34A, RPL37B, RPS29A, RPL19B, RPS10B, RPS25A, RPL31A, RPS18B, RPS4A, RPL23B, RPL36A, RPL14A, RPL40B, RPL27A, RPL40A, RPS30A, RPS6B, RPS19A, RPL43A, RPL29, RPL33A, RPL33B, RPL35B, RPS26B, RPS19B, RPS21B, RPS16A, RPL21A, RPS23B, RPL7A, DYN2, RPL26A, RPS24B, RPS30B, RPS8A, RPS29B, RPL6A, RPL14B, RPS24A, RPS26A, RPS27B, YNL050C, RPL24A, RPS16B, RPS11B, RPL42A, RPS18A, RPL23A, RPS17B, RPS17A, RPL42B, RPS6A, RPS8B, RPL35A, RPL24B, RPS25B, YDL012C, RPL21B, RPL31B, RPL43B, NHP6B, RPS4B, RPL20B, RPL19A, YBL059W, MUD1, RPL2B, RPS27A, LSM7, RAD14, IWR1, APS3, PCC1, MOB2, RPS9A, RUB1, YJLO41W, MRPL44, VMA10, UBC13, BET1, RPS7B, YSC84, RPL32, KEI1, RPS9B, LSM2, PRE3, RPS7A, TMA20, TAD3, RPL25, RPL17A, RPSOA, RPL17B, COX4, RPS21A, VPS29, RPL30, RPL6B, YOP1, SEC14, OST5, RPL16A, RPS14A, RPL16B, STO1, ERD2, RPP1B, RPSOB, COF1, VPS75, RPL13A, RPL2A, RPL36B, RPS23A

Not enriched MND1, HOP2, PCH2, SAE3, REC107, MTR2, RPL18A, MATa1, NCE101, MMS2, SNC1, AIM11, SFT1, SMD2, YDR381C-A, HFM1, RPL7B, NOG2, TAF14, SPO1, HNT2, DCN1, NYV1, CNB1, UBC5, MEI4, UBC8, DMC1, YLR211C, MAF1, OM14, LSB3, RPO26, POP8, RIM1, BIG1, RPS14B, RRT8, AMA1, DID4, COX5B, MRK1, CMC2, UBC9, YPR063C, MOB1, UBC12, GCR1, IST1, RPL22B, DTD1, SCS22, ERV41, KIN28, SEC17, TDA5, RPL18B, ERV1, HNT1, MPT5, GLC7, BOS1, YRA1, RPS13, QCR10, ARP2, SPT14, ECM33, TEF4, APE2, ASC1, SAR1, SAC6, CIN2, YBR220C, SRB2, PMI40, TUB1, DBP2, IMD4, CPT1, YIP3, YPRO98C, EPT1, RPS22B

Ambiguous YOS1, GIM5, RPL28, RPS11A, ARP9, YHR097C, TAN1, YML6, UBC4, PHO85, NCB2, TUB3, QCR9, EFB1, AML1, NMD2, RBS1, GOT1, ACT1, TFC3, RFA2, PFY1, RPL22A, ARF2, SEC27

Insufficient data YOLO47C, REC114, YBR225C-A, SRC1

Relative intron enrichment with RNase P mutation at $37^{\circ} \mathrm{C}$ is indicated via visual inspection of transcript map data. Quantitative analysis of microarray data, which is a composite of probes in exons and introns for each RNA, can be found in the Supplemental Data. Information on intron content is drawn from the Ares Lab Yeast Intron Database: http://metarray.ucsc.edu/yeast_intron_db/.

selected mRNA intron regions and to determine the nature of the RNAs that were accumulating in RNase P mutant samples. Figure 4 shows Northern blots of RNA from both wt and ts strains that were grown for $2 \mathrm{~h}$ at $30^{\circ} \mathrm{C}$ or $37^{\circ} \mathrm{C}$. Figure 4 shows total RNA probed for ribosomal protein mRNA and nonribosomal protein mRNA that contain introns with probes that annealed to the coding sequences (CDS). Accumulation of more slowly migrating bands than the mRNAs was observed for all intron-containing mRNAs tested, having sizes consistent with failure to remove the intron. Since these Northern blots were carried out with probes complementary to $3^{\prime}$ exons, RT-PCR from the introns to the $5^{\prime}$ exons or $5^{\prime}$ UTR was used to confirm the accumulation of unspliced pre-mRNAs rather than intermediates lacking $5^{\prime}$ exons (data not shown). The accumulation in premRNAs is accompanied by a slight but consistent drop in abundance of the mature-sized mRNAs relative to an Scr1 small cytoplasmic RNA loading control. Thus, it is possible that the pre-mRNA accumulates either because of a mild defect in splicing efficiency or a failure to efficiently destroy pre-mRNAs that have not entered the splicing pathway (Bousquet-Antonelli et al. 2000; Sayani et al. 2008).

\section{Shortening of RNAs}

An additional effect of the RNase P mutation was discovered when the sizes of small RNAs were examined by Northern blot. In probing the U6 snRNA signal as a loading control on high-resolution denaturing gels, we noticed that there was a small size difference in $\mathrm{U} 6$ in the ts strain relative to the wt strain. This analysis was subsequently carried out repeatedly for all of the nuclear spliceosome
snRNAs, as well as two RNAs found primarily in the cytoplasm, the Scrl RNA (signal recognition particle RNA) and the $5 \mathrm{~S}$ ribosomal RNA. There was a 2-4-nt shortening of the RNAs observed for RNAs that were small enough for this difference to be resolved (Fig. 5A). Shortening of the small RNAs is consistent with $3^{\prime}-5^{\prime}$ exonuclease trimming until a substantial block is reached due to RNA or RNP structure (Brow 2002), and we used primer extension to confirm that the $5^{\prime}$ ends of U4 and U6 RNAs were unaffected (Fig. 5B). Levels of the small RNAs do not change significantly so this slight trimming does not result in the complete degradation of these RNAs (Fig. 5C).

It is not obvious why an RNase P defect would affect all of these RNAs. They are primarily found in different cellular compartments, involved in different processes, bound by different proteins, and synthesized by different RNA polymerases (RNA polymerase III for U6, 5S, and Scr1; RNA polymerase II for the other RNAs). The only clear commonality is that they are made in the nucleus, suggesting that the shortening might occur there. It is interesting to note that the one short RNA tested that appears unaffected is tRNA, along with its precursors (Supplemental Fig. S1). A reason could be that pre-tRNAs and tRNAs are routinely exposed to $3^{\prime}$ exonuclease attack in wild-type cells, but are rebuilt by CCA addition and aminoacylation at the $3^{\prime}$ termini, which might repair any damage and seal them against further attack.

\section{DISCUSSION}

In this study, we identified a broad and diverse set of noncoding RNAs that accumulate with a mutation in the 

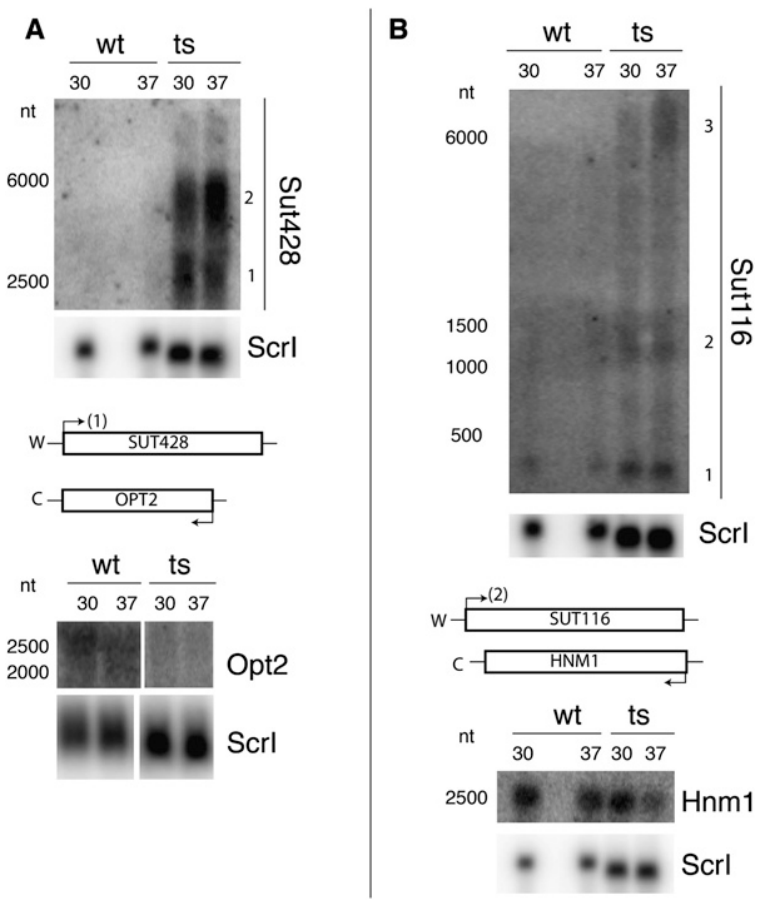

FIGURE 3. Antisense RNA accumulation and overlapping mRNA de-enrichment with an RNase P mutation. Total RNA isolated from replicate cultures of wild-type (wt) or RNase P mutant (ts) samples grown at either $30^{\circ} \mathrm{C}$ or $37^{\circ} \mathrm{C}$ are shown separated on $1.4 \%$ denaturing agarose gels with subsequent Northern blot analysis. Sizes (in nucleotides, nt) were estimated from known markers (Materials and Methods), and W and C strands are as in Figure 1. (A) Northern blots were probed for Sut428 or Opt2 RNAs, reprobing for Scr1 RNA as a loading control. $(B)$ Northern blots were probed for Sut116 or Hnml and reprobed for Scrl as a loading control. In both cases shown, the SUT loci accumulated RNA that differs from previous annotations, which were used for this data set (Xu et al. 2009). Numbers are shown indicating different RNA species. Importantly, the RNA species most consistent with established annotation is indicated at the transcription site on the loci diagram below the Northern blots: Sut428 (1) and Sut116 (2). Also, the "sense" mRNA is shown significantly de-enriched in both panels (see also Fig. 1).

catalytic subunit of RNase P. There is increasing evidence that long, noncoding RNAs (lncRNAs) serve regulatory functions in eukaryotes (Mercer et al. 2009; Ponting et al. 2009; Lee 2010; Ponting and Belgard 2010; van Leeuwen and Mikkers 2010), although the mechanisms by which the lncRNA transcripts are turned over are only beginning to be elucidated. Originally, the widespread occurrence of CUTs and SUTs in S. cerevisiae was difficult to interpret in light of the lack of a small interfering RNA (siRNA) pathway for RNA or the equivalent of the Schizosaccharomyces pombe chromatin modification pathway, although recent observations suggest that alternative chromatin modification pathways might be engaged (Camblong et al. 2007; Berretta et al. 2008; Houseley et al. 2008).

Confirming that these RNAs are RNase P substrates in vivo is difficult given that in vitro studies (Chamberlain et al. 1996; Coughlin et al. 2008; Marvin et al. 2011) have shown that nuclear RNase P can bind and cleave singlestranded RNA at multiple positions without clear sequence or structural requirements. Our in vitro study of cleavage preferences deliberately chose both sense and antisense RNAs across a region where the balance was affected by RNase P mutations, showing that RNase P could bind all segments across the region and cleave RNAs from both strands at multiple places (Camblong et al. 2007; Coughlin et al. 2008; Marvin et al. 2011). Thus, we are confident that RNase $\mathrm{P}$ is potentially capable of cleaving all of the RNAs that accumulate in the ts mutant strain, if it is allowed access to the deproteinized RNA. Although it is formally possible that the RNAs are accumulating due to some indirect effect of the RNase $\mathrm{P}$ mutation elevating promiscuous transcription from many sites in the genome, the most likely hypothesis is loss of normal participation by RNase P in RNA turnover.

The question of whether RNase $\mathrm{P}$ normally does cut these unstable RNAs in vivo to speed their turnover, or whether their accumulation in the RNase P mutant is more of an indirect effect, is difficult to approach. We explored the possibility that RNase P might be part of a complex that includes other enzymes known to participate in nuclear RNA turnover (e.g., exosome or TRAMP components) (for review, see Houseley and Tollervey 2009). Previous work has shown that the exosome uses both exonuclease and endonuclease activity for degradation of highly structured RNAs (Lebreton et al. 2008), and one could envision the RNase $\mathrm{P}$ active site having been adapted to serve this function. However, rapid, low-stringency affinity isolation of RNase $\mathrm{P}$ complexes and sensitive proteomic analysis showed a large number of co-isolating proteins, but these did not include significant amounts of any obvious protein partners that are known to participate in RNA turnover (Supplemental Table S2). Thus, if RNase P is acting in concert with other nucleolytic activities, it does not appear to result in stable complexes with a high percentage of the RNase P.

In previous studies, the removal of the nuclear component of the exosome, Rrp6, resulted in a significant accumulation of a large number of ncRNAs (Jacquier 2009; Xu et al. 2009; Lardenois et al. 2011). The accumulation of noncoding RNAs that we observe with our RNase P mutant is not as widespread as in this earlier work, and contains RNAs from some regions not previously annotated. In addition, RNAs from some loci in the RNase P mutant strain are clearly larger and more heterogeneous than previously annotated. This lack of congruity between the RNase P mutant and the RRP6 deletion accumulations suggests that RNase $\mathrm{P}$ might intersect the function of the exosome, but operate independently in turning over lncRNA. Given that RNase P can recognize both highly structured RNA and preferred sites in less structured sequences, the subset of CUTs/SUTs that accumulate could have nonobvious features or protein partners in vivo that mark them for cleavage. Thus, our 
Intron Containing mRNA

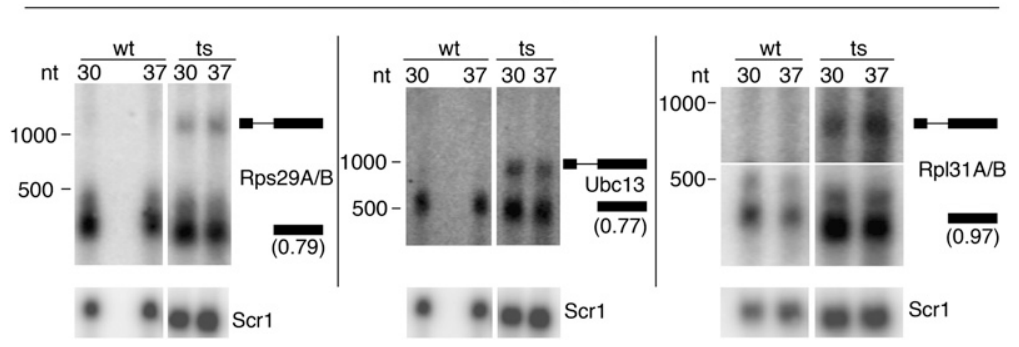

FIGURE 4. Confirmation of pre-mRNA accumulation in an RNase P mutant strain. Total RNA was separated using $1.4 \%$ denaturing agarose gels and subjected to Northern blot analysis. Indicated mRNAs were probed with oligos specific to $3^{\prime}$-exon regions. Total RNA is shown for wild-type (wt) and RNase P mutant (ts) strains grown at either $30^{\circ} \mathrm{C}$ or $37^{\circ} \mathrm{C}$. RNA size markers are indicated next to each blot (Materials and Methods). The predicted positions of pre-mRNA and mature mRNA are shown next to the bands on the blots. For Rps29A/B the pre-mRNA cartoon indicates the 5' UTR intron. Mature mRNA levels are not significantly enriched in the RNase P mutant strain when normalized to internal Scr1 RNA control levels (values range from 0.6-fold to 1.0-fold), but new bands appear at positions predicted to be the indicated pre-mRNA. The presence of 5' exons, as well as introns and 3' exons, was confirmed by RT-PCR (data not shown).

results are consistent with RNase $\mathrm{P}$ possibly playing a role in the degradation of a select subgroup of CUT and SUT RNAs, although further work is needed to determine how RNase P carries out this role.

The other major type of RNA that was shown to accumulate with the RNase $\mathrm{P}$ mutation was intron-containing pre-mRNA. These pre-mRNA species are similar to the CUTs/SUTs only in that both species are relatively transient under wild-type conditions. The observed accumulation of pre-mRNA introns was not completely unprecedented, as a previous study showed accumulation of precursors to intron-encoded box C/D snoRNAs, consistent with an RNase $\mathrm{P}$-mediated pathway for excising the intronic snoRNAs that does not proceed through a spliced intermediate (Villa et al. 2000; Coughlin et al. 2008). The much broader accumulation of intron-containing mRNAs that we were able to detect using higher-density microarrays could have resulted from one of at least two effects. First, the RNase P mutation could be indirectly and mildly compromising the splicing apparatus (for review, see Wahl et al. 2009), which would be consistent with the shortening of the snRNA components of the spliceosome, but would not explain shortening of the other RNAs or the accumulation of lncRNAs. Alternatively, a small population of unspliced pre-mRNAs might normally fail to enter the splicing pathway and require nuclear turnover involving RNase P. The observed low-level association of RNase $\mathrm{P}$ with a wide variety of transcripts from spliced genes (Coughlin et al. 2008) and the concomitant accumulation of many CUTs and SUTs would be consistent with the second interpretation.

There is not a clear explanation for how RNase P mutations might indirectly cause most of the effects we see here. The best understood effect of this RNase P mutation is the accumulation of pre-tRNA, long known to be the evolutionarily conserved RNase $\mathrm{P}$ substrate from bacteria to vertebrates. The accumulation of pre-tRNAs is one possible indirect mechanism for the accumulation of other RNAs and/or the slight shortening of RNAs that we observe in our study. Accumulated pre-tRNAs might compete for RNA-binding proteins that would otherwise protect many small RNAs in the nucleus and possibly contribute to rapid turnover of CUTs, SUTs, and "escaped" intron-containing pre-mRNAs. One obvious candidate for such a protein was the ubiquitous $\mathrm{La}$ protein, Lhp1 in $S$. cerevisiae, which binds to the $3^{\prime}$ ends of RNA polymerase III transcripts and other poly(U) sequences (Pannone et al. 1998, 2001; Mayes et al. 1999). Although overexpression of Lhp1 did not suppress the observed shortening of small RNAs (data not shown), it remains possible that it or another RNA-binding complex (e.g., Lsm) is competed for by the accumulated pre-tRNAs (Mayes et al. 1999; Beggs 2005). An alternative interpretation might be that the accumulation of RNAs that are normally turned over with the help of RNase P (CUTs, SUTs, and premRNAs) frees up exonuclease capacity or competes for RNA-binding proteins, either of these resulting in the increased exonuclease attack on normally resistant RNAs.

RNase $\mathrm{P}$ has evolved to recognize the structure of pretRNA and cleave at a precise position relative to the tertiary structure (Frank and Pace 1998; Walker and Engelke 2006). However, it appears that nuclear RNase $\mathrm{P}$ has gained additional RNA-binding and cleavage capability due to increased protein content of the RNA core (Marvin et al. 2011). The simplest hypothesis for why noncoding RNAs, and possibly unspliced pre-mRNAs, accumulate is that they are normally cleaved by RNase $\mathrm{P}$ for rapid turnover, but this raises an interesting question of how they become exposed to the enzyme. Localization of RNase P RNA by fluorescent in situ hybridization shows that the enzyme is present primarily in the nucleolus in S. cerevisiae (Bertrand et al. 1998), where the majority of the tRNA genes and pretRNAs are also found (Thompson 2003). It is possible that smaller quantities of active enzyme are also more dispersed in the nucleoplasm, or that the noncoding RNAs must traffic to the nucleolus to encounter RNase P. The related complex that processes pre-rRNAs, RNase MRP, is also primarily in the nucleolus, but also has been detected in the cytoplasm, where it appears to be involved in turnover of a set of mRNAs that are entirely distinct from the ones that accumulate in our hands with the RNase P mutant (Gill et al. 2006). No RNase $P$ has ever been detected by our group in the cytoplasm through fluorescent tags on either the RNA subunit or the unique protein subunit, Rpr2p, but we are unable to definitively exclude lesser, non-nucleolar pools (Bertrand et al. 1998). 
A

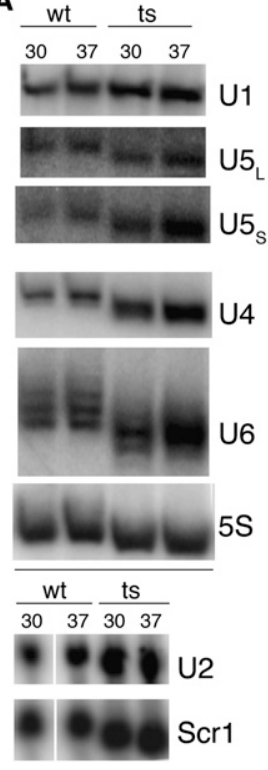

B

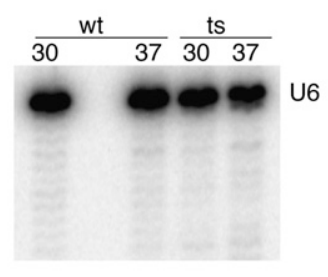

C

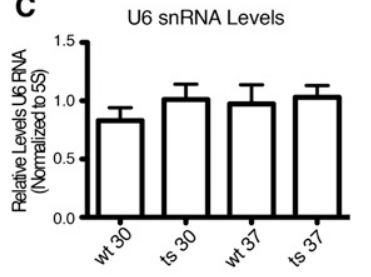

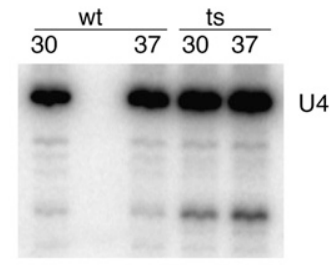

U4 SnRNA Levels

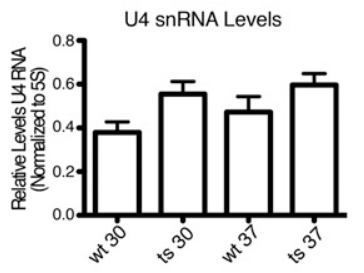

protein that is found in RNase $\mathrm{P}$, but not RNase MRP (see Marvin et al. 2011). Thus, while multiple proteins and the RNA subunit in the holoenzyme might be involved in contacting unstructured RNA substrates, Rpr2p is a prime candidate for providing contacts by which RNase $\mathrm{P}$ recognizes features in nontRNA substrates.

\section{MATERIALS AND METHODS}

\section{Yeast strains}

S. cerevisiae strain JLY1 (MATa ade2-1 his311,15 leu2-3,112 trp1-1 ura3-1 can1-100 RPR1::HIS3), with a background of W3031A, was the parent strain with RPR1 on a LEU2marked plasmid. We investigated the effect of a temperature-sensitive mutation in Rprlr at position $\mathrm{G}_{207} \mathrm{G}_{211}$ (Pagán-Ramos et al. 1996). A secondary, neutral sequence alteration was present in the $\mathrm{P} 3$ region of $R P R 1$ (position 69-75: AUCAGAU to CAGGACG) as a unique hybridization marker in both the wild-type and the ts RPR1 RNA sequences.

\section{Yeast growth}

The synthetic dropout media (SD-His) was used for growth of JLY1 strains. For analysis of RPR1 mutant effects $\left(\mathrm{G}_{207} \mathrm{G}_{211}\right)$, previous studies have identified the optimal growth conditions to observe RNase $\mathrm{P}$ defects (Coughlin et al. 2008). Both wild-type and

It was recently shown that RNase MRP has a limited sequence preference for a $\mathrm{C}$ at position +4 relative to the site of cleavage (Esakova et al. 2011). This preference does not seem to occur with RNase $\mathrm{P}$, which appears to recognize RNA with little regard to primary sequence (Marvin et al. 2011). Why might RNase $P$ and RNase MRP recognize different types of RNA substrate? Although the two enzymes share eight of the same protein subunits, there are one or two proteins that are distinctive to each enzyme and the RNAs are different, although evolutionarily related (for review, see Walker and Engelke 2006). It is certainly possible that the RNA subunit differences could play a role in contributing to the observed differences in RNA recognition between the two complexes. However, the structure of the bacterial enzyme shows that, as expected, the RNA subunit recognizes primarily the structured portion of pre-tRNAs, while single-stranded extensions are in contact with the single small protein (Reiter et al. 2010). Consistent with this, the in vitro activity of the nuclear RNase P suggests that two or more of the nine protein subunits are involved in binding non-tRNA substrates, but not necessarily pre-tRNA substrates. Interestingly, one of these proteins is Rpr2p, the sole temperature-sensitive yeast were grown into mid-log phase then diluted and shifted to $37^{\circ} \mathrm{C}$ in pre-warmed SD-His media for $2 \mathrm{~h}$.

\section{Microarray analysis}

Hot acid phenol was used to isolate total RNA from yeast grown at either $30^{\circ} \mathrm{C}$ or $37^{\circ} \mathrm{C}$ (Köhrer and Domdey 1991). RNA was treated with Turbo DNase I per the manufacturer's protocol (Ambion). DNase was then inactivated using inactivation reagent (Ambion). UV absorbance at 260/280 nm was used to measure concentration of samples.

For first-strand cDNA synthesis, $20 \mu \mathrm{g}$ of total RNA was mixed with $1.72 \mu \mathrm{g}$ of random hexamers and $0.034 \mu \mathrm{g}$ of oligo(dT) primer and incubated for $10 \mathrm{~min}$ at $70^{\circ} \mathrm{C}$ followed by $10 \mathrm{~min}$ at $25^{\circ} \mathrm{C}$, then transferred to ice. The synthesis included 2000 units of SuperScript II Reverse Transcriptase, $50 \mathrm{mM}$ Tris- $\mathrm{HCl}, 75 \mathrm{mM}$ $\mathrm{KCl}, 3 \mathrm{mM} \mathrm{MgCl} 2,0.01 \mathrm{M} \mathrm{DTT}$, dNTP + dUTP mix (0.5 mM for dCTP, dATP, and dGTP; $0.4 \mathrm{mM}$ for dTTP; and $0.1 \mathrm{mM}$ for dUTP; [Invitrogen]), and $20 \mu \mathrm{g} / \mathrm{mL}$ actinomycin $\mathrm{D}$ in a total volume of $105 \mu \mathrm{L}$. Actinomycin D was added during reverse transcription (Perocchi et al. 2007). The reaction was carried out sequentially for $10 \mathrm{~min}$ at $25^{\circ} \mathrm{C}, 30 \mathrm{~min}$ at $37^{\circ} \mathrm{C}, 30 \mathrm{~min}$ at $42^{\circ} \mathrm{C}$, and $10 \mathrm{~min}$ at $70^{\circ} \mathrm{C}$ for heat inactivation. Samples were then subjected to RNase treatment of $20 \mathrm{~min}$ at $37^{\circ} \mathrm{C}$ (30 units of 
RNase H [Epicentre], 60 units of RNase Cocktail [Ambion]). First-strand cDNA was purified using the MinElute PCR purification kit (QIAGEN), and $4 \mu \mathrm{g}$ was fragmented and labeled using the GeneChip WT Terminal labeling kit (Affymetrix) according to the manufacturer's protocol. The labeled cDNA samples were denatured in a volume of $300 \mu \mathrm{L}$ containing $50 \mathrm{pM}$ control oligonucleotide B2 (Affymetrix) and Hybridization mix (GeneChip Hybridization, Wash and Stain kit; Affymetrix) of which 250 $\mu \mathrm{L}$ was hybridized per array ( $S$. cerevisiae yeast tiling array; Affymetrix, PN 520055). Hybridizations were carried out for $16 \mathrm{~h}$ at $45^{\circ} \mathrm{C}$ with $60 \mathrm{rpm}$ rotation. The staining was carried out using the GeneChip Hybridization, Wash and Stain kit with fluidics protocol FS450_0001 in an Affymetrix Fluidics station. The cDNA hybridizations are available at ArrayExpress (http://www.ebi.ac. uk/arrayexpress/) under the accession number E-MEXP-3140 and the array design under A-AFFY-116.

Genomic DNA (gDNA) was prepared from the same background strain (W3031A) that was used for total RNA preparation above to normalize signal from the RNA (Huber et al. 2006). Only the probes matching exactly and uniquely to the W303 genome were considered. Transcript boundaries were taken from the Supplemental Table 3 of $\mathrm{Xu}$ et al. (2009). For each transcript, expression level was estimated by the midpoint of the "shorth" (shortest interval that covers half the values) of the normalized probe intensities lying within the transcript. A searchable database of expression results from the microarray experiment can be found at http://steinmetzlab.embl.de/engelkeArray/index. html.

\section{Northern blots of RNA}

Northern blots were carried out using both denaturing polyacrylamide and denaturing agarose gel systems. Denaturing polyacrylamide Northern blots were carried out as performed previously (Coughlin et al. 2008). Agarose-formaldehyde gels (Sambrook et al. 2001) were used to fractionate total RNA followed by transfer to Nytran Supercharge membranes using a TurboBlotter apparatus (Schleicher \& Schuell Biosciences). An RNA ladder (Lonza) was loaded in the same way as total RNA and run for size estimation.

Specific oligonucleotide probes (Supplemental Table S3) were labeled with $\left[\gamma_{-}{ }^{32} \mathrm{P}\right]$ ATP using polynucleotide kinase (NEB) per the manufacturer's protocol, hybridized to membranes, and subsequently washed per the manufacturer's protocol for Nytran SuperCharge membranes (Schleicher \& Schuell Biosciences). Signal was detected using a Typhoon Trio+ imager and quantitated using ImageJ software (http://rsbweb.nih.gov/ij/).

Analysis of the sizes of total cellular poly(A) tracts after digestion of total RNA with a titration of RNase A followed by Northern blot analysis using radiolabeled oligo(dT) (15 nt) as a probe, also suggested that mRNA might be slightly shortened by approximately five or more adenosine residues (data not shown), but the inherent length heterogeneity of the poly(A) tails made this difficult to interpret with confidence.

Total RNA that was isolated from wt and ts yeast strains was reverse-transcribed using Omniscript reverse transcriptase per the manufacturer's protocol (QIAGEN) with radiolabeled U4 and U6 oligos (Supplemental Table S3) to determine if these RNAs are being trimmed at the $5^{\prime}$ ends. After separation on denaturing gels, samples were exposed to a phosphor screen with visualization using a Typhoon Trio+ imager.

\section{SUPPLEMENTAL MATERIAL}

Supplemental material is available for this article.

\section{ACKNOWLEDGMENTS}

We thank Zhenyu Xu for help with microarray analysis. In addition, we thank Francoise Stutz for discussions concerning antisense Pho84 RNA. This work was supported by grant GM034869 (to D.R.E.), and an UM Cellular Biotechnology Training Grant T32-GM08353 and a fellowship from the Horace H. Rackham Graduate School (both to M.C.M.). Funding was also provided by grants from the NIH and Deutsche Forschungsgemeinschaft (to L.M.S.) and NIH Grant P41 RR011823 (to J.R.Y.). This is TSRI Manuscript \#21257.

Received March 19, 2011; accepted April 28, 2011.

\section{REFERENCES}

Alifano P, Rivellini F, Piscitelli C, Arraiano CM, Bruni CB, Carlomagno MS. 1994. Ribonuclease $\mathrm{E}$ provides substrates for ribonuclease P-dependent processing of a polycistronic mRNA. Genes Dev 8: 3021-3031.

Altman S, Wesolowski D, Guerrier-Takada C, Li Y. 2005. RNase P cleaves transient structures in some riboswitches. Proc Natl Acad Sci 102: 11284-11289.

Beggs JD. 2005. Lsm proteins and RNA processing. Biochem Soc Trans 33: 433-438.

Berretta J, Pinskaya M, Morillon A. 2008. A cryptic unstable transcript mediates transcriptional trans-silencing of the Ty1 retrotransposon in S. cerevisiae. Genes Dev 22: 615-626.

Bertrand E, Houser-Scott F, Kendall A, Singer RH, Engelke DR. 1998. Nucleolar localization of early tRNA processing. Genes Dev 12: 2463-2468.

Bothwell AL, Stark BC, Altman S. 1976. Ribonuclease P substrate specificity: Cleavage of a bacteriophage phi80-induced RNA. Proc Natl Acad Sci 73: 1912-1916.

Bousquet-Antonelli C, Presutti C, Tollervey D. 2000. Identification of a regulated pathway for nuclear pre-mRNA turnover. Cell 102: 765-775.

Brow DA. 2002. Allosteric cascade of spliceosome activation. Annu Rev Genet 36: 333-360.

Camblong J, Iglesias N, Fickentscher C, Dieppois G, Stutz F. 2007. Antisense RNA stabilization induces transcriptional gene silencing via histone deacetylation in S. cerevisiae. Cell 131: 706-717.

Chamberlain JR, Pagán-Ramos E, Kindleberger DW, Engelke DR. 1996. An RNase P RNA subunit mutation affects ribosomal RNA processing. Nucleic Acids Res 24: 3158-3166.

Chamberlain JR, Lee Y, Lane WS, Engelke DR. 1998. Purification and characterization of the nuclear RNase P holoenzyme complex reveals extensive subunit overlap with RNase MRP. Genes Dev 12: 1678-1690.

Coughlin DJ, Pleiss JA, Walker SC, Whitworth GB, Engelke DR. 2008. Genome-wide search for yeast RNase P substrates reveals role in maturation of intron-encoded box C/D small nucleolar RNAs. Proc Natl Acad Sci 105: 12218-12223.

David L, Huber W, Granovskaia M, Toedling J, Palm CJ, Bofkin L, Jones T, Davis RW, Steinmetz LM. 2006. A high-resolution map of transcription in the yeast genome. Proc Natl Acad Sci 103: 5320-5325.

Esakova O, Perederina A, Quan C, Berezin I, Krasilnikov AS. 2011. Substrate recognition by ribonucleoprotein ribonuclease MRP. RNA 17: 356-364.

Frank DN, Pace NR. 1998. Ribonuclease P: Unity and diversity in a tRNA processing ribozyme. Annu Rev Biochem 67: 153-180.

Giegé R, Florentz C, Dreher TW. 1993. The TYMV tRNA-like structure. Biochimie 75: 569-582. 
Gill T, Aulds J, Schmitt ME. 2006. A specialized processing body that is temporally and asymmetrically regulated during the cell cycle in Saccharomyces cerevisiae. J Cell Biol 173: 35-45.

Gimple O, Schön A. 2001. In vitro and in vivo processing of cyanelle tmRNA by RNase P. Biol Chem 382: 1421-1429.

Hansen A, Pfeiffer T, Zuleeg T, Limmer S, Ciesiolka J, Feltens R, Hartmann RK. 2001. Exploring the minimal substrate requirements for trans-cleavage by RNase P holoenzymes from Escherichia coli and Bacillus subtilis. Mol Microbiol 41: 131-143.

Hartmann RK, Heinrich J, Schlegl J, Schuster H. 1995. Precursor of C4 antisense RNA of bacteriophages P1 and P7 is a substrate for RNase P of Escherichia coli. Proc Natl Acad Sci 92: 5822-5826.

Houseley J, Tollervey D. 2009. The many pathways of RNA degradation. Cell 136: 763-776.

Houseley J, Rubbi L, Grunstein M, Tollervey D, Vogelauer M. 2008. A ncRNA modulates histone modification and mRNA induction in the yeast GAL gene cluster. Mol Cell 32: 685-695.

Huber W, Toedling J, Steinmetz LM. 2006. Transcript mapping with high-density oligonucleotide tiling arrays. Bioinformatics 22: 1963 1970.

Jacquier A. 2009. The complex eukaryotic transcriptome: unexpected pervasive transcription and novel small RNAs. Nat Rev Genet 10: 833-844.

Juneau K, Miranda M, Hillenmeyer ME, Nislow C, Davis RW. 2006. Introns regulate RNA and protein abundance in yeast. Genetics 174: 511-518.

Jung YH, Lee Y. 1995. RNases in ColE1 DNA metabolism. Mol Biol Rep 22: 195-200.

Köhrer K, Domdey H. 1991. Preparation of high molecular weight RNA. Methods Enzymol 194: 398-405.

Komine Y, Kitabatake M, Yokogawa T, Nishikawa K, Inokuchi H. 1994. A tRNA-like structure is present in 10Sa RNA, a small stable RNA from Escherichia coli. Proc Natl Acad Sci 91: 9223-9227.

Koutmou K, Zahler N, Kurz J, Campbell F, Harris M, Fierke C. 2009. Protein-precursor tRNA contact leads to sequence-specific recognition of $5^{\prime}$ leaders by bacterial Ribonuclease P. J Mol Biol 396: 195-208.

Lardenois A, Liu Y, Walther T, Chalmel F, Evrard B, Granovskaia M, Chu A, Davis RW, Steinmetz LM, Primig M. 2011. Execution of the meiotic noncoding RNA expression program and the onset of gametogenesis in yeast require the conserved exosome subunit Rrp6. Proc Natl Acad Sci 108: 1058-1063.

Lebreton A, Tomecki R, Dziembowski A, Séraphin B. 2008. Endonucleolytic RNA cleavage by a eukaryotic exosome. Nature 456: $993-$ 996.

Lee JT. 2010. The $\mathrm{X}$ as model for RNA's niche in epigenomic regulation. Cold Spring Harb Perspect Biol 2: a003749. doi: 10.1101/cshperspect.a003749.

Lee JY, Rohlman CE, Molony LA, Engelke DR. 1991. Characterization of RPR1, an essential gene encoding the RNA component of Saccharomyces cerevisiae nuclear RNase P. Mol Cell Biol 11: 721730.

Li Y, Altman S. 2003. A specific endoribonuclease, RNase P, affects gene expression of polycistronic operon mRNAs. Proc Natl Acad Sci 100: 13213-13218.

Liu F, Altman S. 1994. Differential evolution of substrates for an RNA enzyme in the presence and absence of its protein cofactor. Cell 77: $1093-1100$.

Marvin MC, Walker SC, Fierke CA, Engelke DR. 2011. Binding and cleavage of unstructured RNA by nuclear RNase P. RNA (this issue). doi: 10.1261/rna.2633611.

Mayes AE, Verdone L, Legrain P, Beggs JD. 1999. Characterization of Sm-like proteins in yeast and their association with U6 snRNA. EMBO J 18: 4321-4331.

Mercer TR, Dinger ME, Mattick JS. 2009. Long non-coding RNAs: insights into functions. Nat Rev Genet 10: 155-159.

Neil H, Malabat C, d'Aubenton-Carafa Y, Xu Z, Steinmetz LM, Jacquier A. 2009. Widespread bidirectional promoters are the major source of cryptic transcripts in yeast. Nature 457: 1038-1042.
Pagán-Ramos E, Lee Y, Engelke DR. 1996. A conserved RNA motif involved in divalent cation utilization by nuclear RNase P. RNA 2: $1100-1109$.

Pannone BK, Xue D, Wolin SL. 1998. A role for the yeast La protein in U6 snRNP assembly: evidence that the La protein is a molecular chaperone for RNA polymerase III transcripts. EMBO J 17: 7442-7453.

Pannone BK, Kim SD, Noe DA, Wolin SL. 2001. Multiple functional interactions between components of the Lsm2-Lsm8 complex, U6 snRNA, and the yeast La protein. Genetics 158: 187-196.

Peck-Miller KA, Altman S. 1991. Kinetics of the processing of the precursor to $4.5 \mathrm{~S}$ RNA, a naturally occurring substrate for RNase P from Escherichia coli. J Mol Biol 221: 1-5.

Perocchi F, Xu Z, Clauder-Münster S, Steinmetz LM. 2007. Antisense artifacts in transcriptome microarray experiments are resolved by actinomycin D. Nucleic Acids Res 35: e128. doi: 10.1093/nar/gkm683.

Planta RJ, Mager WH. 1998. The list of cytoplasmic ribosomal proteins of Saccharomyces cerevisiae. Yeast 14: 471-477.

Ponting CP, Belgard TG. 2010. Transcribed dark matter: meaning or myth? Hum Mol Genet 19: R162-R168.

Ponting CP, Oliver PL, Reik W. 2009. Evolution and functions of long noncoding RNAs. Cell 136: 629-641.

Reiter NJ, Osterman A, Torres-Larios A, Swinger KK, Pan T, Mondragón A. 2010. Structure of a bacterial ribonuclease P holoenzyme in complex with tRNA. Nature 468: 784-789.

Roy SW, Gilbert W. 2006. The evolution of spliceosomal introns: patterns, puzzles and progress. Nat Rev Genet 7: 211-221.

Sambrook J, Fritsch EF, Maniatis T. 2001. Molecular cloning: A laboratory manual, 3rd ed. Cold Spring Harbor Laboratory Press, Cold Spring Harbor, NY.

Sayani S, Janis M, Lee CY, Toesca I, Chanfreau GF. 2008. Widespread impact of nonsense-mediated mRNA decay on the yeast intronome. Mol Cell 31: 360-370.

Smith JK, Hsieh J, Fierke CA. 2007. Importance of RNA-protein interactions in bacterial ribonuclease $\mathrm{P}$ structure and catalysis. Biopolymers 87: 329-338.

Spingola M, Grate L, Haussler D, Ares M. 1999. Genome-wide bioinformatic and molecular analysis of introns in Saccharomyces cerevisiae. RNA 5: 221-234.

Thompson M. 2003. Nucleolar clustering of dispersed tRNA genes. Science 302: 1399-1401.

Vanacova S, Stefl R. 2007. The exosome and RNA quality control in the nucleus. EMBO Rep 8: 651-657.

van Leeuwen S, Mikkers H. 2010. Long non-coding RNAs: Guardians of development. Differentiation 80: 175-183.

Villa T, Ceradini F, Bozzoni I. 2000. Identification of a novel element required for processing of intron-encoded box C/D small nucleolar RNAs in Saccharomyces cerevisiae. Mol Cell Biol 20: 13111320.

Wahl MC, Will CL, Lührmann R. 2009. The spliceosome: Design principles of a dynamic RNP machine. Cell 136: 701-718.

Walker SC, Engelke DR. 2006. Ribonuclease P: The evolution of an ancient RNA enzyme. Crit Rev Biochem Mol Biol 41: 77-102.

Wilusz JE, Freier SM, Spector DL. 2008. 3' end processing of a long nuclear-retained noncoding RNA yields a tRNA-like cytoplasmic RNA. Cell 135: 919-932.

Xiao S, Day-Storms JJ, Srisawat C, Fierke CA, Engelke DR. 2005. Characterization of conserved sequence elements in eukaryotic RNase P RNA reveals roles in holoenzyme assembly and tRNA processing. RNA 11: 885-896.

Xiao S, Hsieh J, Nugent RL, Coughlin DJ, Fierke CA, Engelke DR. 2006. Functional characterization of the conserved amino acids in Poplp, the largest common protein subunit of yeast RNases $\mathrm{P}$ and MRP. RNA 12: 1023-1037.

Xu Z, Wei W, Gagneur J, Perocchi F, Clauder-Münster S, Camblong J, Guffanti E, Stutz F, Huber W, Steinmetz LM. 2009. Bidirectional promoters generate pervasive transcription in yeast. Nature 457: 1033-1037.

Yang L, Altman S. 2007. A noncoding RNA in Saccharomyces cerevisiae is an RNase P substrate. RNA 13: 682-690. 

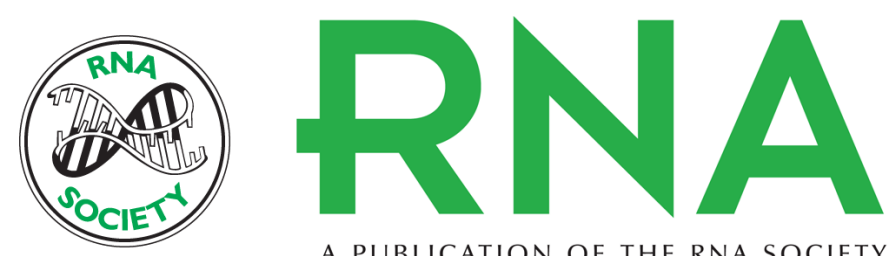

A PUBLICATION OF THE RNA SOCIETY

\section{Accumulation of noncoding RNA due to an RNase P defect in Saccharomyces cerevisiae}

Michael C. Marvin, Sandra Clauder-Münster, Scott C. Walker, et al.

RNA 2011 17: 1441-1450 originally published online June 10, 2011

Access the most recent version at doi:10.1261/rna.2737511

\section{Supplemental http://rnajournal.cshlp.org/content/suppl/2011/05/26/rna.2737511.DC1 \\ Material}

Related Content

Binding and cleavage of unstructured RNA by nuclear RNase $\mathbf{P}$ Michael C. Marvin, Scott C. Walker, Carol A. Fierke, et al.

RNA August , 2011 17: 1429-1440

References This article cites 62 articles, 25 of which can be accessed free at:

http://rnajournal.cshlp.org/content/17/8/1441.full.html\#ref-list-1

Articles cited in:

http://rnajournal.cshlp.org/content/17/8/1441.full.html\#related-urls

License

Email Alerting Receive free email alerts when new articles cite this article - sign up in the box at the Service top right corner of the article or click here. 